\title{
Epidemiology of Cardiovascular Risk Factors in Asian Countries
}

\author{
Ho N. Nguyen; Akira Fujiyoshi, MD, PhD; \\ Robert D. Abbott, PhD; Katsuyuki Miura, MD, PhD
}

\begin{abstract}
The distribution and burden of 5 conventional risk factors (elevated blood pressure, high total cholesterol, diabetes, obesity/overweight and smoking) for cardiovascular diseases (CVD) were reviewed in 10 selected Asian countries, in addition to the United Kingdom and the United States. Over the past 3 decades, age-standardized systolic blood pressure was on the decline in high-income countries but on the rise in low- to middle-income countries. Similar patterns were observed for total cholesterol levels, although the absolute levels remained higher in high-income countries. A pronounced increase in the prevalence of diabetes mellitus was seen in most of the Asian countries, corresponding to an increase in the levels of body mass index. The number of smokers declined markedly with time, particularly in men, in some selected Asian countries (Japan, Singapore, China, Vietnam). However, the prevalence of current smokers for all countries in 2011 remained excessive. The population-attributable risks for stroke and ischemic heart were highest for high blood pressure, followed by total cholesterol, obesity, and smoking. Evidence suggests that in both Asia and the West, no country is in sufficient control of any of these factors and that intervention programs to alter their effect on CVD are of equal importance. (Circ $J$ 2013; 77: 2851-2859)
\end{abstract}

Key Words: Blood pressure; Body mass index; Diabetes mellitus; Smoking; Total cholesterol

C ardiovascular diseases (CVDs) have multiple risk factors. ${ }^{1}$ Conventional risk factors include elevated blood pressure (BP), high serum cholesterol, diabetes mellitus (DM), and tobacco use. According to the INTERHEART study, the joint contribution of hypertension, adverse lipid profiles, DM, smoking and obesity accounted for nearly $80 \%$ of CVD. ${ }^{2}$ Modification of these conventional risk factors plays a significant role in both primary and secondary prevention for CVD. ${ }^{3,4}$

It has been well documented that these risk factors generally act similarly in both Western and Asian countries. ${ }^{5-7}$ However, the distribution of each risk factor may differ not only between Asia and other areas of the world but also within Asia itself. In this review, we describe the prevalence and trends of the conventional CVD risk factors in different regions of Asia. We focused on 4 metabolic risk factors (BP, total cholesterol (TC), DM, and obesity) and 1 behavioral risk factor (smoking) because of their strong associations with CVD. We also examined the effect of each risk factor on CVD death. For comparison with Western countries, we included similar data from the United Kingdom (UK) and the United States (USA).

\section{Methods}

We describe data from 10 Asian countries and the UK and
USA. The criteria for country selection were somewhat arbitrary, largely being based on geographical location (Central Asia, South Asia, Southeast Asia, East Asia, and Middle East), income level (low, middle, and high, defined by the World Bank) ${ }^{8}$ and data availability.

Data for the 4 metabolic risk factors were extracted from studies of the Global Burden of Metabolic Risk Factors of Chronic Diseases Collaborating Group, 2011.9-12 For the most part, we used this published data source because it contains the most recently available and reliable information about national trends for men and women over a long period of time from 1980 to 2008. Data are also systematically standardized and validated to enhance comparability across countries.

Prevalence estimates for smoking in 2011 are cited from the World Health Organization (WHO) report on the global tobacco epidemic, 2013. ${ }^{13}$ Not all the detailed data for trends on smoking were available for the selected countries. Hence, we combined available information from reports by the WHO and the Organization for Economic Cooperation and Development (OECD) and individual national surveys for 4 Asian countries, being Japan, Singapore, China and Vietnam, from 1984 to 2010. ${ }^{13-22}$ Data for the UK and the USA were retrieved from OECD reports ${ }^{14-17}$ and national statistics. ${ }^{23,24}$ All the results are presented as age-standardized mean values or percent prevalence unless otherwise stated.

Received October 15, 2013; accepted October 15, 2013; released online November 15, 2013

Department of Health Science (H.N.N., A.F., K.M.), Center for Epidemiologic Research in Asia (R.D.A., K.M.), Shiga University of Medical Science, Otsu, Japan

Mailing address: Akira Fujiyoshi, MD, PhD, MPH, Department of Health Science, Shiga University of Medical Science, Seta-Tsukinowa-cho, Otsu 520-2192, Japan. E-mail: afujiy@belle.shiga-med.ac.jp

ISSN-1346-9843 doi:10.1253/circj.CJ-13-1292

All rights are reserved to the Japanese Circulation Society. For permissions, please e-mail: cj@j-circ.or.jp 


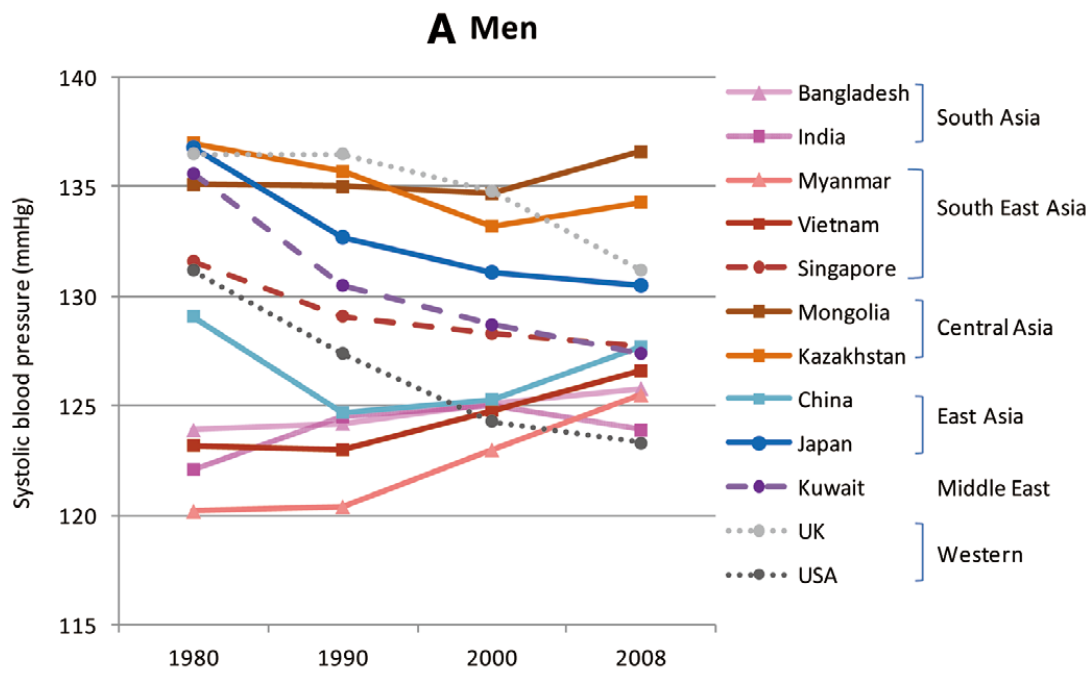

B Women

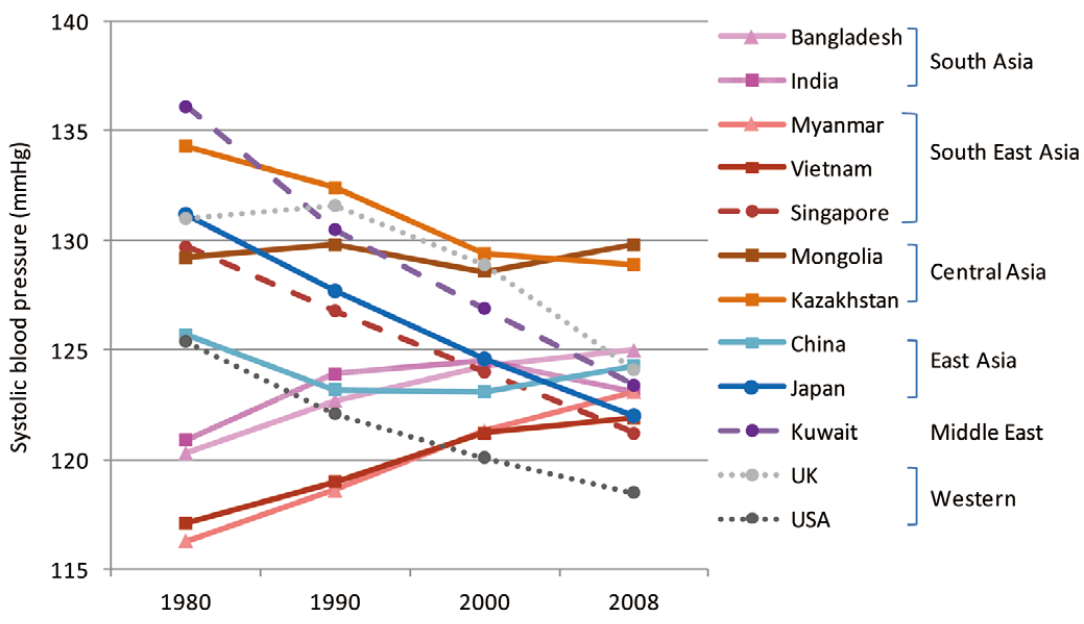

Figure 1. The 30-year trends in agestandardized mean systolic blood pressure $(\mathrm{mmHg})$ in the selected countries for men (A) and women (B). The countries are grouped by income level: high (circle), middle (square) and low (triangle). ${ }^{12}$

\section{Risk Factors for CVD in Asian Populations}

\section{Blood Pressure}

Among the established risk factors, hypertension and elevated $\mathrm{BP}$ have the greatest effect on CVD risk in Asia. In the AsiaPacific region, $66 \%$ of deaths from CVD could be attributed to hypertension. ${ }^{25}$

Figure 1 presents the 30-year change in mean systolic BP (SBP) from 1980. ${ }^{12}$ For both men and women, mean SBP levels decreased over time in high-income countries in Asia, in a pattern similar to that in the UK and USA. Levels of SBP dropped considerably from 1980 to $1990(2.5-5.0 \mathrm{mmHg}$ per decade for men and 3.0-5.6 mmHg per decade for women), followed by more moderate declines in the next 20 years $(0.6-1.8 \mathrm{mmHg}$ per decade for men and 2.6-3.6 $\mathrm{mmHg}$ per decade for women). In contrast, low- and middle-income countries experienced a rise in mean SBP, being most evident in Southeast Asia (Vietnam and Myanmar) over the past 20 years $(1.6-2.5 \mathrm{mmHg}$ per decade for men and $0.7-2.7 \mathrm{mmHg}$ per decade for women). In all the selected countries, women had lower SBP levels than men. Substantial differences by sex were seen in Vietnam, Japan, and Mongolia, with a difference ranging from 3.6 to
$8.5 \mathrm{mmHg}$. A similar sex-difference was observed in the UK and USA. In 1980, female SBP in China was similar to that in the USA, but began to rise after 1990 to levels that exceeded the USA values by $5 \mathrm{mmHg}$ in 2008 .

Cross-Sectional SBP Levels in 2008 In 2008, the highest SBP levels were observed among men and women in Mongolia and Kazakhstan (2 middle-income countries in Central Asia). In contrast, the SBP levels in most of the high-income countries (Japan, Singapore, Kuwait, the UK) tended to fall in the middle to low ranges among all 12 countries. Levels were lower in Bangladesh and India (South Asia) and in Myanmar and Vietnam (Southeast Asia). Although the cross-sectional SBP levels in these latter countries were equal to or slightly higher than the USA, 30-year trends were on the rise with no sign of abating.

The observed decline in SBP in high-income countries such as Japan, the UK, and USA are likely related to greater access to health care and awareness programs that emphasize BP control and reductions in dietary salt intake, and increased pharmacological intervention. ${ }^{26-29}$ However, even in such developed countries, treatment rates and BP control rates among treated patients are far from acceptable: approximately up to 


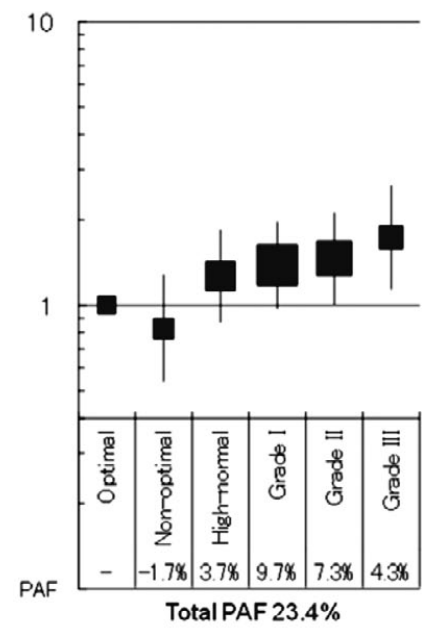

Very elderly (75-89y)

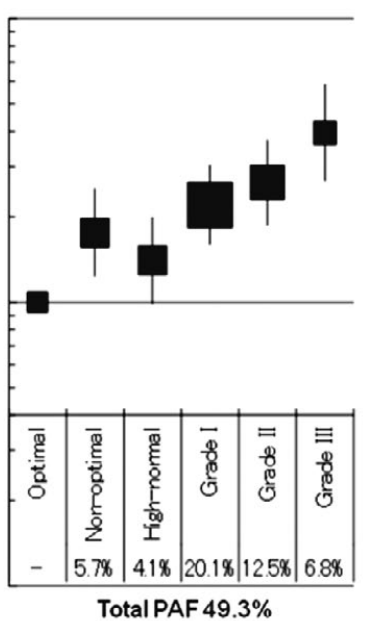

Elderly (65-74y)

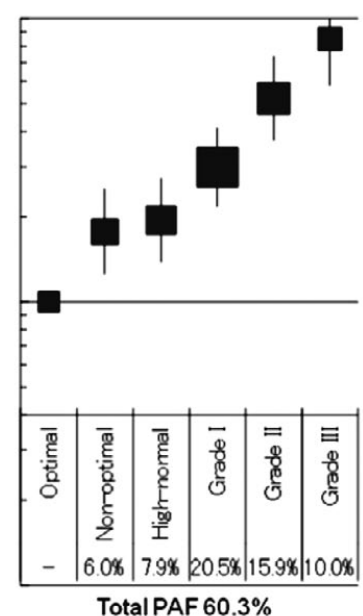

Middle-age (40-64y)

Figure 2. Hazard ratio and population-attributable fractions (PAFs) of total cardiovascular deaths according to blood pressure (BP) categories by 3 age groups. The graphs are based on individual-based pooled data from 10 cohorts ( $n=67,309$, age 40-89 years) across Japan. ${ }^{32}$ BP categories were defined as: 'Optimal', systolic BP $<120 \mathrm{mmHg}$ and diastolic BP $<80 \mathrm{mmHg}$; the corresponding systolic and diastolic BP values were 120-129 and 80-84 mmHg for 'Non-optimal,' 130-139 or 85-89 mmHg (whichever was greater) for 'High-normal,' 140-159 or 90-99 mmHg for 'Grade I hypertension,' 160-179 or 100-109 mmHg for 'Grade II hypertension' and $\geq 180$ or $\geq 110 \mathrm{mmHg}$ for 'Grade III hypertension, respectively. A solid square is centered on the hazard ratio point and sized in proportion to the number of deaths. The vertical line represents the $95 \%$ confidence interval $(\mathrm{Cl})$. Hazard ratios (HR) were referenced to the Optimal BP category and adjusted for potential confounders. The PAFs indicate that $23-60 \%$ of cardiovascular deaths could have been prevented had this entire population, age range 40-89 years, kept their BP at the optimal level through their lifestyle (ie, primary prevention).

$65 \%$ and $35 \%$ in $\operatorname{Japan}^{30}$ and $73 \%$ and $69 \%$ in the USA, ${ }^{27}$ respectively. In other low- and middle-income Asian countries, undiagnosed and untreated hypertension is likely more common, considering the background conditions of limited access to effective treatments and care for chronic diseases. ${ }^{31}$

Evidence from a large community-dwelling sample of 65,000 Japanese men and women suggests that a considerable proportion of CVD deaths could have been avoided had proper measures been taken to maintain healthy BP levels (systolic/diastolic $\mathrm{BP}<120 / 80 \mathrm{mmHg}$ ) through their lifestyle (Figure 2) ${ }^{32}$ This illustrates the importance of primary prevention of hypertension regardless of age.

\section{Serum Cholesterol}

Dyslipidemia is a prominent risk factor that promotes the development of atherosclerotic CVD, especially coronary artery disease (CAD). Lipid profiles that include low-density lipoprotein-cholesterol (LDL-C) or the ratio of TC to high-density lipoprotein-cholesterol (HDL-C) are often the preferred measure of CVD risk in basic CVD screening. ${ }^{11}$ However, data on LDL-C and HDL-C are scarce in most Asian countries and often only the TC value is available. Regardless, TC remains a good predictor of CVD, and even TC levels lower than guidelines from the Adult Treatment Panel III have been associated with an increased incidence of CAD. ${ }^{33}$ Therefore, TC levels were used as an indicator of dyslipidemia among the selected countries for this report.

Between 1980 and 2008, mean TC decreased with varying degrees in most countries (Figure 3). ${ }^{11}$ Greater falls in serum TC occurred in high-income countries (except Japan), in Central Asia, the UK and USA for both sexes. Japan and China witnessed rises in mean TC over the years, although their levels differ in the absolute sense. South Asian countries had smaller declines. For the remaining countries, including East and Southeast Asia, mean TC levels rose for both sexes.

Cross-Sectional TC Levels in 2008 In 2008, TC levels generally corresponded with income levels of a country. For example, high-income countries tended to have the highest TC levels (ranging from $5.2-5.3 \mathrm{mmol} / \mathrm{L}$ [200-205 mg/dl]) for both sexes. First and second highest among low- and middleincome countries were Kazakhstan and Mongolia (in Central Asia) with TC levels ranging from 4.9-4.7 mmol/L (189$181 \mathrm{mg} / \mathrm{dl}$ ). Low-income countries (ie, Myanmar and Bangladesh) had TC levels $<4.5 \mathrm{mmol} / \mathrm{L}$ ( $174 \mathrm{mg} / \mathrm{dl})$. TC levels in women were higher than in men, but the differences were modest $(0-0.2 \mathrm{mmol} / \mathrm{L}[0-7.7 \mathrm{mg} / \mathrm{dl}])$.

The rise in TC levels in Asia is attributable in part to changes in dietary patterns. Nutritional transitions toward a higher intake of fat, foods from animal sources and processed foods have been observed..$^{34,35}$ Japan is an example of a high-income country that has experienced increases in TC levels beginning as early as the $1950 \mathrm{~s} .^{36}$

Statin treatment to lower serum cholesterol has shown a significant benefit in preventing CVD in Caucasian as well as Asian populations. ${ }^{37,38}$ Regardless of notable improvements in recent decades, however, the prevalence of statin use remains low even in the UK and USA where more than $50 \%$ of patients at moderate to high risk of CVD are estimated to receive suboptimal statin treatment. ${ }^{39,40}$ In the REACH study of treatment intensity of individuals with atherothrombosis, patients were generally undertreated with statins in many regions of the world, including Japan, the Middle East and Asia. ${ }^{41}$ 


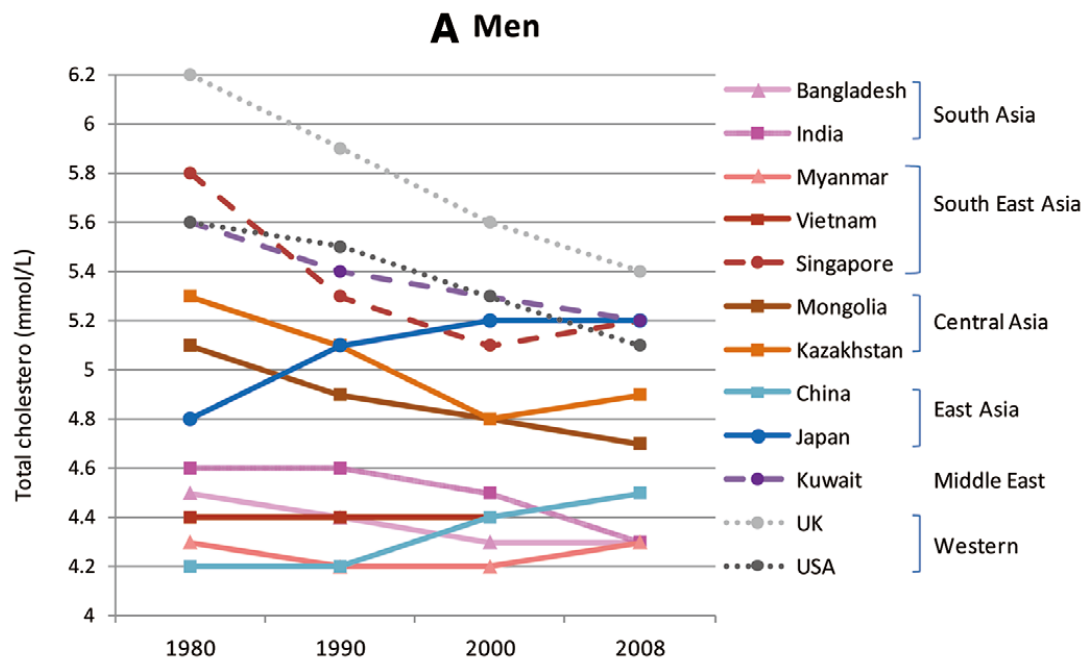

B Women

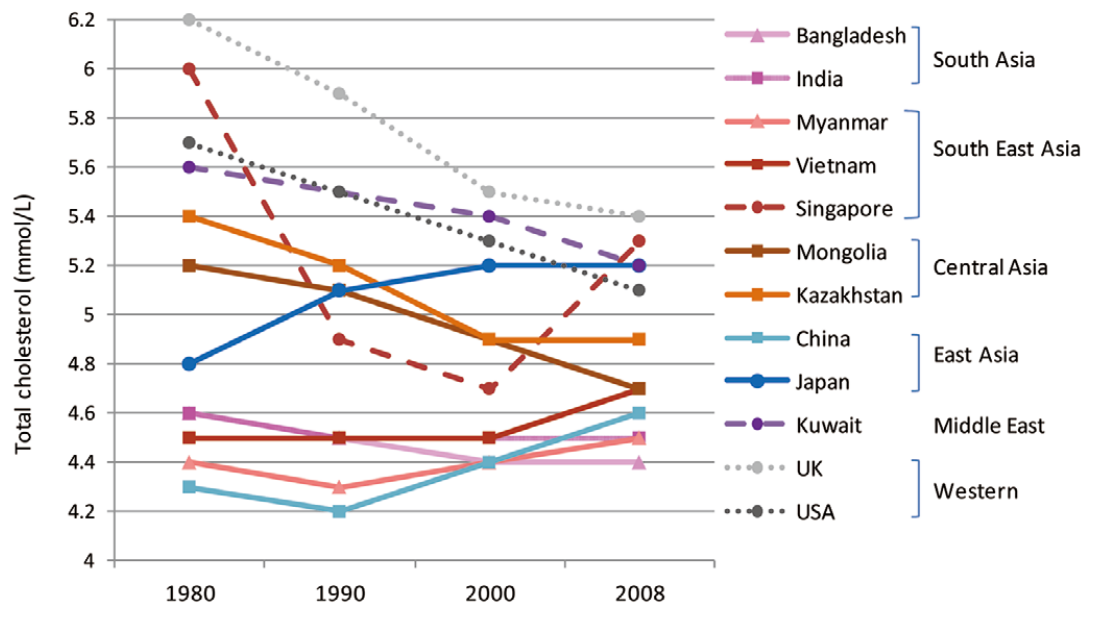

Figure 3. The 30-year trends in agestandardized mean total cholesterol $(\mathrm{mmol} / \mathrm{L})$ in the selected countries for men (A) and women (B). ${ }^{11}$ The countries are grouped by income level: high (circle), middle (square) and low (triangle). To change into $\mathrm{mg} / \mathrm{dl}$, multiply by $38.61(6.2 \mathrm{mmol} / \mathrm{L}=240 \mathrm{mg} / \mathrm{dl}$, $5.2 \mathrm{mmol} / \mathrm{L}=200 \mathrm{mg} / \mathrm{dl}$ ).

\section{Diabetes Mellitus}

$\mathrm{DM}$ is growing as a worldwide pandemic. DM places an individual at higher risk of morbidity and mortality from a variety of disease outcomes. In the pooling of 97 prospective studies, DM was shown to increase the risk of death by up to 3-fold compared with its absence. In addition to CVD as a cause of death, other causes include kidney disease, mental illness, cancer, and sepsis. ${ }^{42}$ In the current report, DM is defined as a fasting plasma glucose level $\geq 7 \mathrm{mmol} / \mathrm{L}(126 \mathrm{mg} / \mathrm{dl})$ or receipt of hypoglycemic therapy or physician diagnosis.

Figure 4 shows the change in DM prevalence in the selected countries from 1980 to 2008. During this period, prevalence increased in the Asian samples, more so in high-income vs. low- and middle-income regions. ${ }^{10}$ Singapore was the only country that experienced a decline in DM prevalence and it was remarkable (from $13.2 \%$ to the present rate of 5.4\%). The most pronounced rise in DM occurred in Kuwaiti men and women, followed by Japanese men and Bangladeshi women. The prevalence of DM in these samples almost doubled over time.

Cross-Sectional DM Prevalence in 2008 In 2008, the prevalence of DM among the Asian countries ranged from $6.1 \%$ to $17.0 \%$ for men and from $4.7 \%$ to $14.8 \%$ for women.
DM remained less prevalent in Japan, Myanmar and Vietnam. It is noteworthy that the prevalence of DM in most of the Asian countries was higher than in the UK, for both men and women.

The cause of DM has been attributed to a variety of modifiable social and lifestyle factors. ${ }^{43}$ In particular, rising rates of obesity have been implicated as a major factor that has contributed to the current DM epidemic. Obesity alone, however, does not fully explain the relatively larger burden of DM in Asia compared with Western countries. The risk of type 2 diabetes may start at a lower body mass index (BMI) for Asians than for Europeans because of the greater frequency in Asia of abdominal obesity and visceral fat accumulation. ${ }^{43-46}$ Other factors that are more dominant in Asia include an increased risk of gestational diabetes ${ }^{47}$ combined with an increased exposure to poor nutrition during the perinatal period and overnutrition in later life. ${ }^{46}$

Obesity Obesity results from high energy intake (from diet) and low energy expenditure (determined by basal metabolic rate, physical activity, and food-induced thermogenesis). As a result of this imbalance, obesity has become a major healthcare concern in both developed and developing coun- 


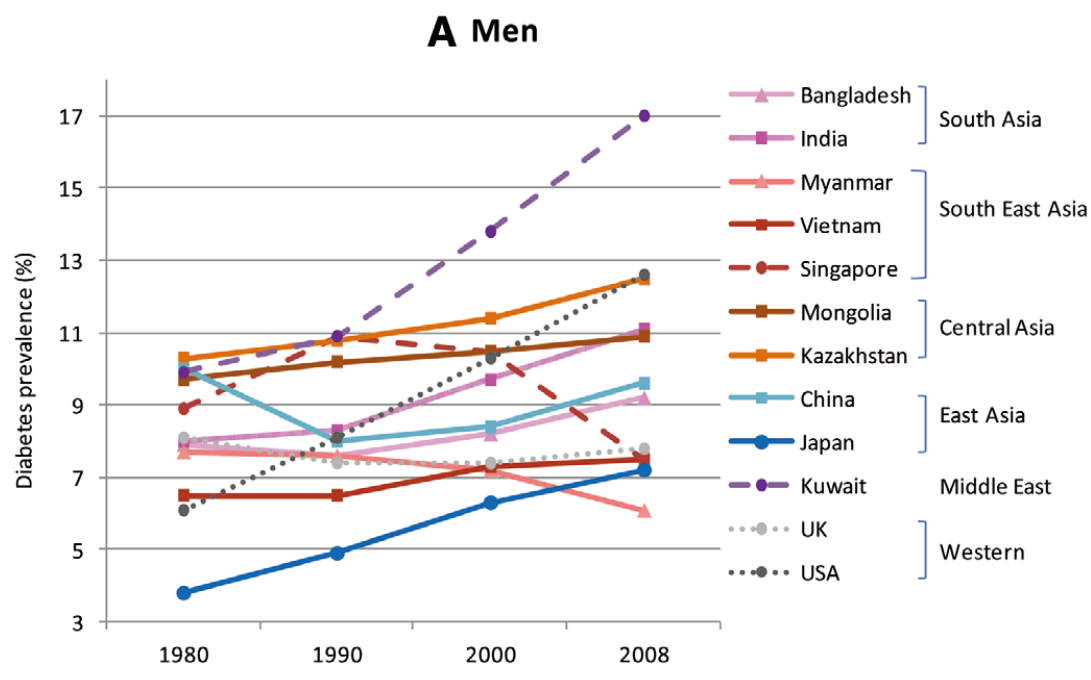

B Women

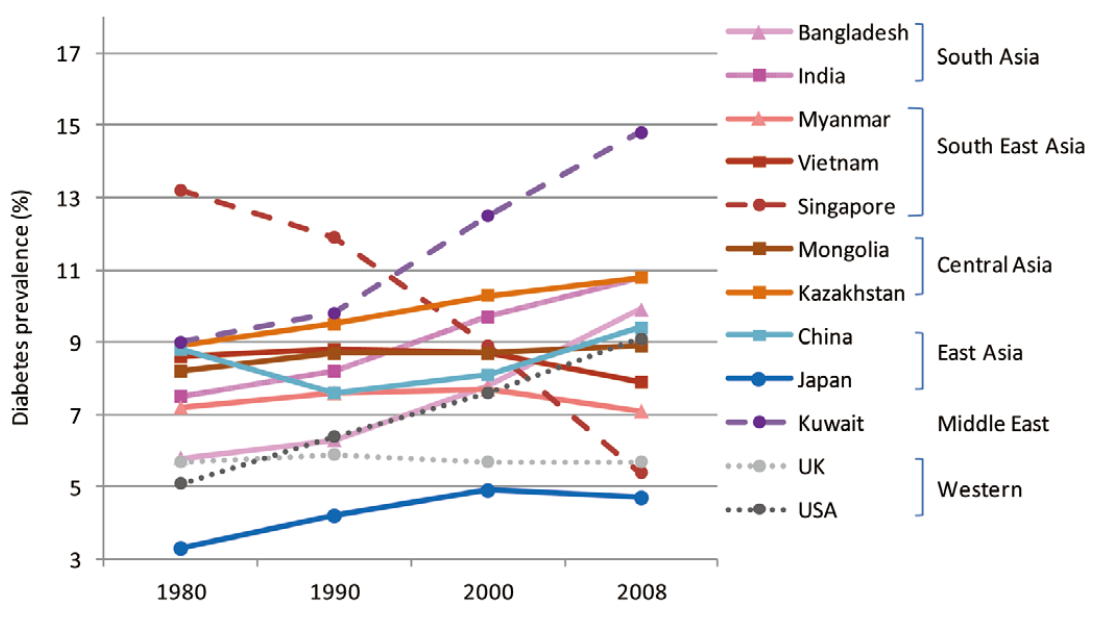

Figure 4. The 30-year trends in agestandardized diabetes prevalence (\%) in the selected countries for men (A) and women (B). The countries are grouped by income level: high (circle), middle (square) and low (triangle). ${ }^{10}$

tries. It is of special concern because of its relationship with CVD and its associated risk factors (eg, hypertension and $\mathrm{DM})$. For the current report, BMI (weight $[\mathrm{kg}] /$ height $\left[\mathrm{m}^{2}\right]$ ) is used as a proxy measure of obesity, as it is reasonably reproducible and easy to obtain.

From 1980 to 2008, mean BMI rose throughout the Asian countries as well as the UK and USA, although the degree of change between countries varied (Figure 5). ${ }^{9}$ Because the increase in BMI has occurred globally, the ranking of countries has been relatively stable, with Kuwait, the UK and USA having the highest BMI levels, with South Asia and Southeast Asia (except for Singapore) having the lowest. It is noteworthy that in 2008, the average BMI of Kuwaiti women exceeded $30 \mathrm{~kg} / \mathrm{m}^{2}$. For Kuwaiti men, the average BMI was slightly lower $\left(29.2 \mathrm{mg} / \mathrm{kg}^{2}\right)$. Mean BMI in Central Asia was also high (reaching $25 \mathrm{mg} / \mathrm{kg}^{2}$ ).

\section{Smoking}

The adverse effects of smoking on health have been proven..$^{48}$ Smoking is causally associated with CVD, cancer, chronic respiratory disease, and probably DM. ${ }^{49}$ Among low- and middleincome countries, it is estimated that more than three-quarters of the total global burden of diseases are caused by smoking. ${ }^{50}$

Figure 6 shows the prevalence of current tobacco smokers aged $\geq 15$ years in 2011 (defined as smoking at the time of the survey, including daily and non-daily smoking). ${ }^{13}$ For men, current smoking exceeded $30 \%$ in all of the selected Asian countries except for India (25\%). In some low- and middleincome countries (Vietnam, Mongolia, China and Bangladesh), smoking prevalence was as high as $50 \%$. Differences in smoking prevalence between low- and middle-income countries and high-income countries were modest.

Smoking was more common by men than by women in Asia, but the ratio of male-to-female smokers differed across countries, ranging from 3:1 in Japan to more than 10:1 in countries such as Bangladesh, Vietnam, and China. In contrast, the ratio was close to $1: 1$ in the UK and USA, a possible consequence of greater financial independence among more Westernized women. ${ }^{6}$

Figure 7 shows the changes in daily smoking in 4 Asian countries (Japan, Singapore, China and Vietnam) and the UK and USA that were observed from 1984 to 2010. Smoking prevalence in men fell markedly in most countries. For example, from 1990 to 2009 , smoking by men more than halved in 


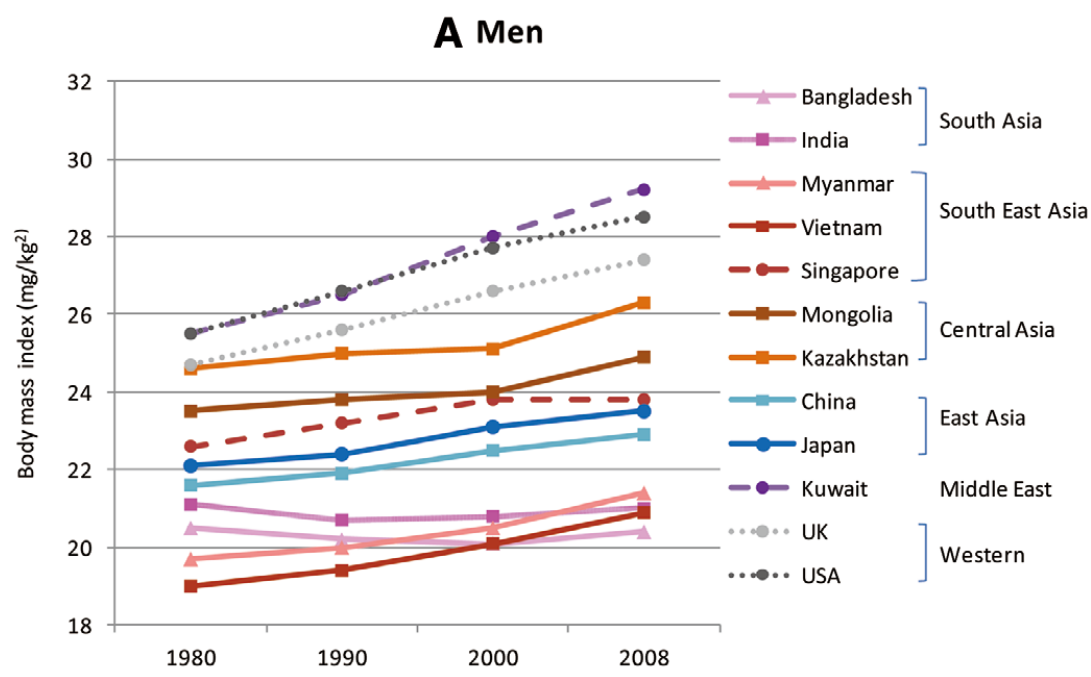

B Women

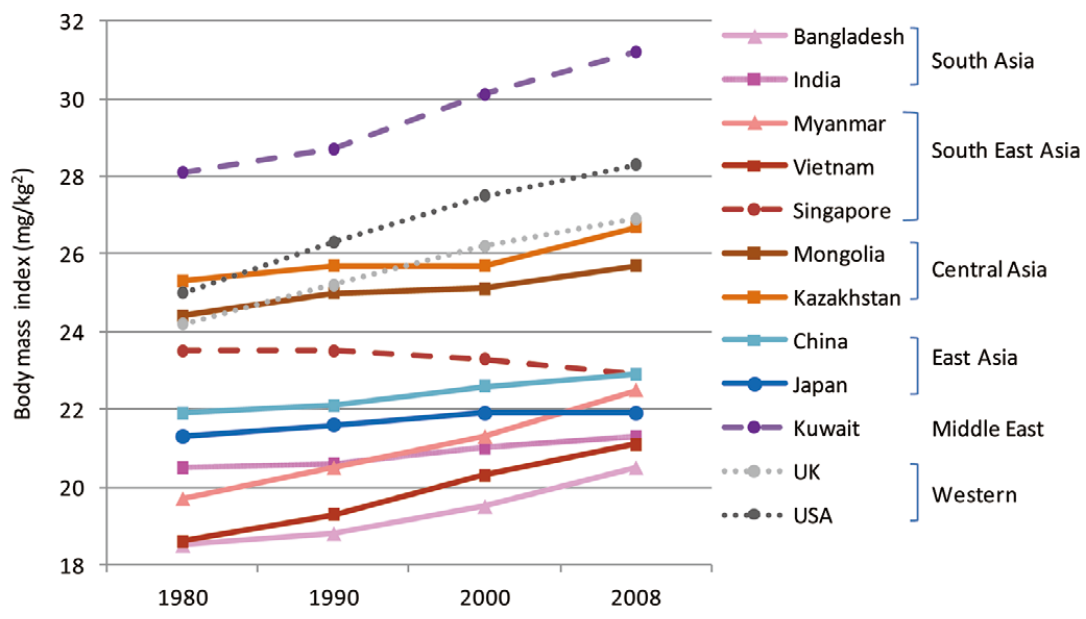

Figure 5. The 30-year trends in agestandardized mean body mass index $\left(\mathrm{kg} / \mathrm{m}^{2}\right)$ in the selected countries for men $(\mathbf{A})$ and women (B). The countries are grouped by income level: high (circle), middle (square) and low (triangle). ${ }^{9}$

Japan (from $70 \%$ to $32 \%$ ). In Asia, smoking by women has been historically low $(<20 \%)$ with very small changes seen over time. In recent years, smoking among Asian men is more common than in the UK and USA, while for women the opposite is true. (Note that the definition used in Figure 7 differs from the one in Figure 6.)

\section{Migration Effects}

Other than genetic predisposition, environmental and lifestyle exposures can have important effects on the development of CVD. Studies in Asian samples after migration to Western countries have generally shown a significant change in the risk of CVD. ${ }^{51,52}$ The ERA JUMP study, comparing 3 communitybased samples of 300 men each, showed that JapaneseAmericans in the USA had a greater frequency of coronary artery calcification and a thicker carotid intima media than Japanese in Japan and even Caucasian men in the USA. ${ }^{53}$ The considerably high estimates observed in the Japanese Americans as compared with Japanese in Japan provide evidence of the importance of the environment on influencing the development of atherosclerotic disease vs. genetic factors. It further suggests that atherosclerosis is highly preventable.
In contrast, migration effects could change risk factors in a beneficial direction. For example, prevalence of hypertension and smoking could decline with migration to the West. Rates of obesity, DM and elevated serum cholesterol, however, could increase. Chinese migrants living in Mauritius had a higher prevalence of CAD, with higher cholesterol levels than those in Beijing, China. Although the latter represents an adverse effect from migration, Chinese migration to Canada resulted in rates of stroke that were similar to general rates for Canadians. Given that Canada has one of the lowest rates of stroke in the world, this provides further evidence that the effect of environmental changes on disease is real. ${ }^{52}$

\section{Effect of Each Risk Factor on CVD in Asian Populations}

To assess the effect of the risk factors on CVD, we used population-attributable fractions (PAFs) reported by the Global Burden Disease (GBD) Project on the global burden of disease. Because of the paucity of pertinent data for PAF of mortality from CVD, countries were grouped into a broader categorization than in previous sections (based on classification by the World 


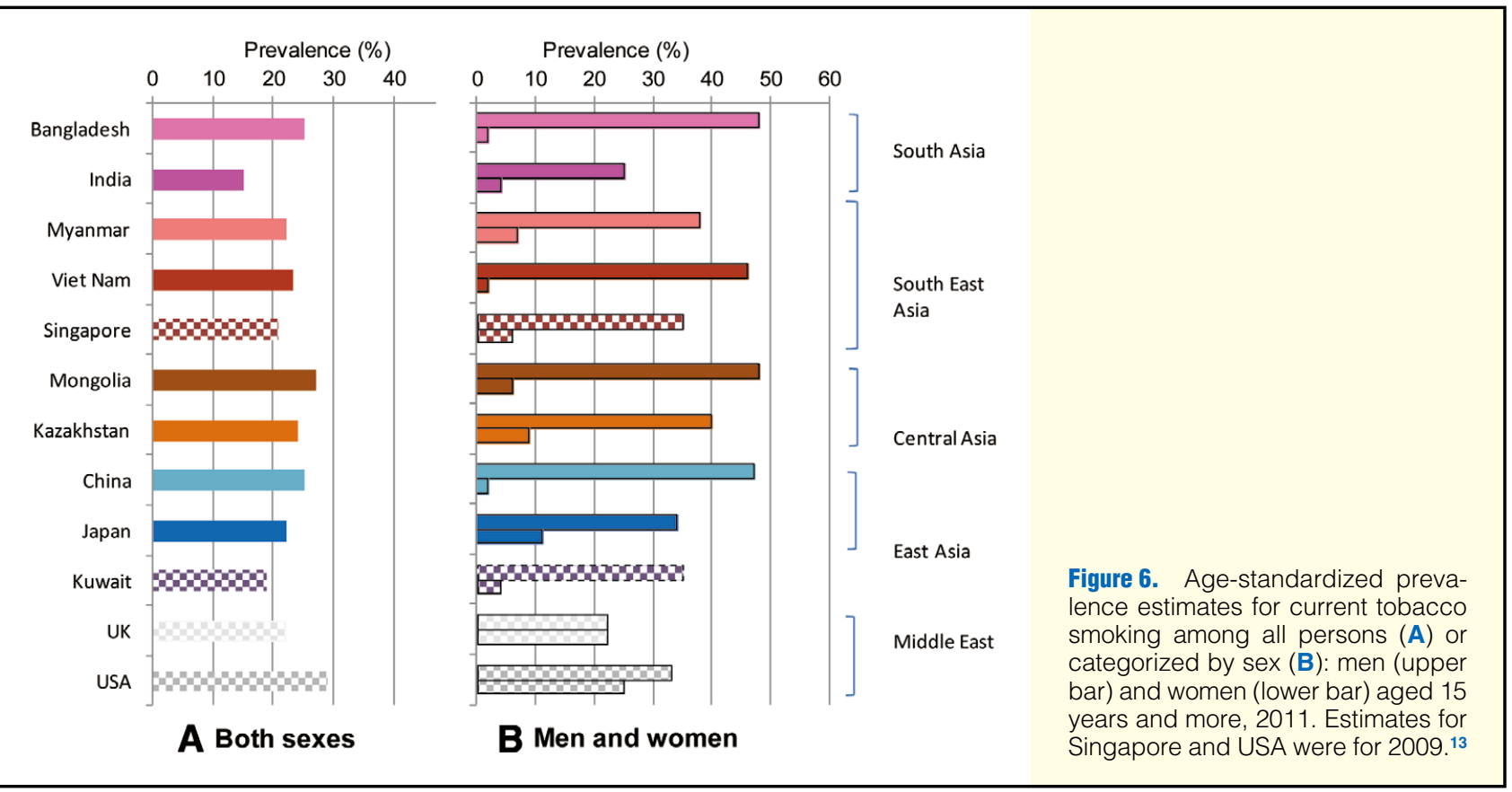
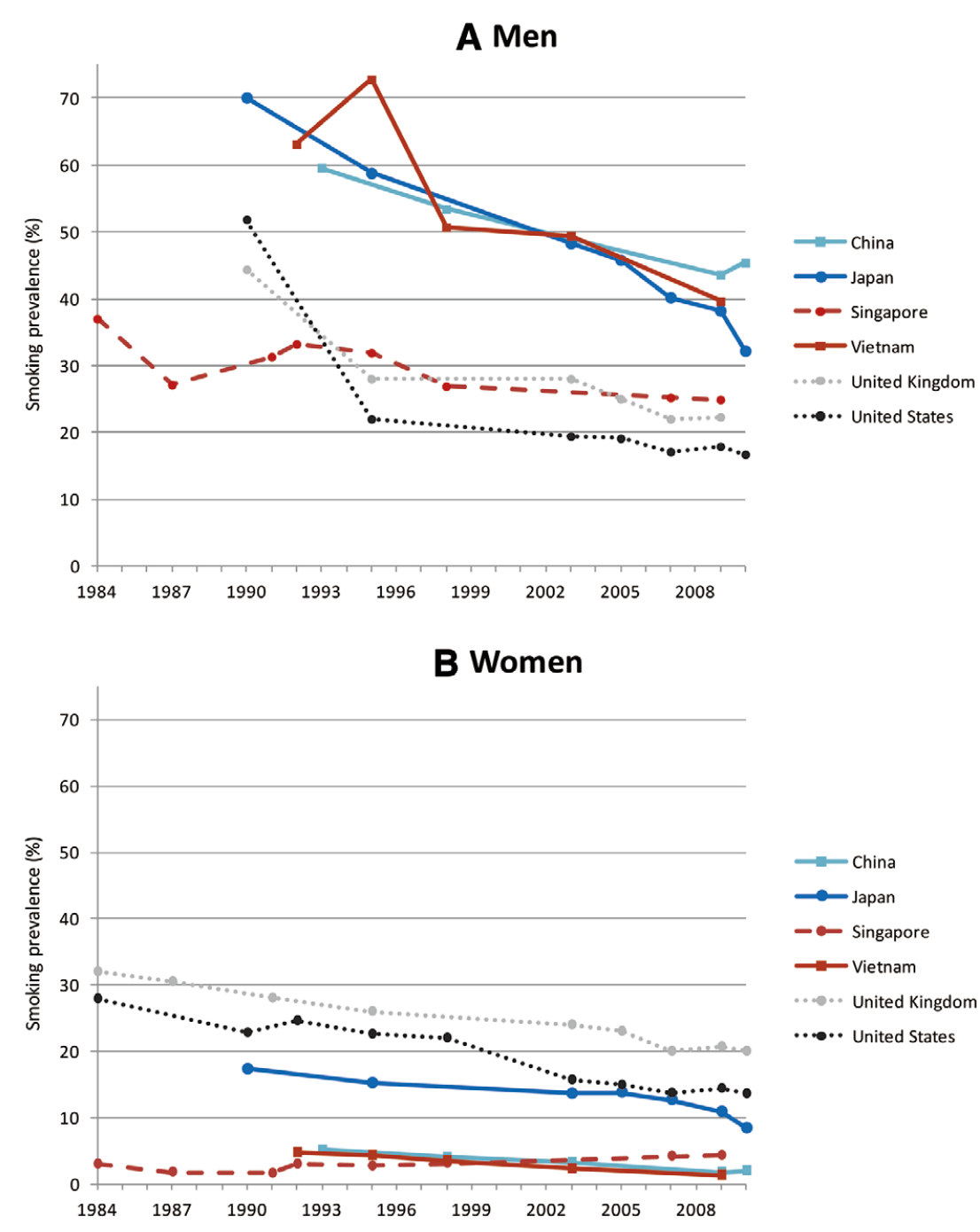

Figure 7. Change in daily smoking prevalence in selected countries for men $(\mathbf{A})$ and women (B). 


\begin{tabular}{|c|c|c|c|c|c|c|c|c|}
\hline & \multicolumn{2}{|c|}{$\begin{array}{l}\text { High blood } \\
\text { pressure }\end{array}$} & \multicolumn{2}{|c|}{ High cholesterol } & \multicolumn{2}{|c|}{$\begin{array}{l}\text { Overweight } \\
\text { and obesity }\end{array}$} & \multicolumn{2}{|c|}{ Smoking } \\
\hline & IHD & Stroke & IHD & Stroke & IHD & Stroke & IHD & Stroke \\
\hline East Asia and Pacific & 41 & 50 & 32 & 8 & 10 & 4 & 6 & 5 \\
\hline Europe and Central Asia & 61 & 69 & 55 & 20 & 24 & 16 & 17 & 14 \\
\hline Middle East and North Africa & 48 & 54 & 47 & 15 & 22 & 11 & 11 & 8 \\
\hline South Asia & 39 & 49 & 43 & 14 & 5 & 3 & 10 & 8 \\
\hline High-income countries & 49 & 54 & 52 & 17 & 19 & 12 & 15 & 10 \\
\hline World & 47 & 54 & 45 & 13 & 15 & 8 & 12 & 8 \\
\hline
\end{tabular}

Global Burden of Disease and Risk Factors (2006). PAF is the proportion of events (such as death) that could have been prevented if the risk of interest was reduced to the lowest population risk. (ie, blood pressure of $115 \mathrm{mmHg}$, total cholesterol of $3.8 \mathrm{mmol} / \mathrm{L}$ [150 mg/dl], BMl of $21 \mathrm{~kg} / \mathrm{m}^{2}$ or no smoking). ${ }^{54}$ According to the World Bank's classification, the 12 selected countries are placed in regions as follows: China, Mongolia, Myanmar, Vietnam: 'East Asia and Pacific region'; Kazakhstan: 'Europe and Central Asia region'; Bangladesh, India: 'South Asia region'; Japan, Kuwait, Singapore, the UK, USA: 'High-income countries'. IHD, ischemic heart disease.

Bank). According to this classification, all the Asian low- and middle-income countries were grouped into 4 categories (East Asia and Pacific, Europe and Central Asia, Middle East and North Africa, and South Asia), with high-income countries as a 5th category. Within each category, PAFs were calculated for the percent of fatal ischemic heart disease (IHD) and stroke that could be attributed to each of the 4 risk factors, except for DM (which was listed as a disease outcome by the GBD)..$^{54}$

Table shows that high BP has large effect on CVD deaths in the Asian regions, accounting for PAF of 39-61\% of IHD and $49-69 \%$ of stroke. High cholesterol had the second highest effect, particularly for IHD, in Asia. Although the PAFs of smoking for IHD and stroke were lower than those of high cholesterol or obesity, it is noteworthy that the effect of smoking on all-cause death, as mentioned earlier, is large. ${ }^{55,56}$

Eastern Europe and Central Asia faced a significantly larger burden of CVD linked to the 4 conventional risk factors compared with the other regions of Asia. Nearly $70 \%$ of stroke deaths in this region were related to high BP, compared with $50 \%$ in East Asia-Pacific and $49 \%$ in South Asia. The effect of being overweight or obese was also high in Eastern Europe and Central Asia, where nearly one-quarter of deaths from fatal IHD were attributable. This finding corresponds with a recent systemic review in the Middle East, suggesting that the 4 risk factors (plus DM) are key determinants of CVD. ${ }^{57}$

Asia has certain characteristics that may affect the pattern of risk factors on CVD burden. Approximately half of the world's population lives in the low- and middle-income countries of East Asia and the Pacific (30\%) and South Asia (20\%). ${ }^{54}$ Limited access to health care among these countries poses enormous challenges to global health. ${ }^{58}$ Rapid epidemiologic transitions, shifting from a predominance of nutritional deficiencies and infectious diseases to noncommunicable disease, have also been observed in these regions. ${ }^{59}$ Although communicable diseases continue to occur with high prevalence, the effect that CVD will have on the limited healthcare resources in these countries is expected to increase.

\section{Conclusions}

In this review of 5 leading CVD risk factors in 10 Asian countries and the UK and USA, we observed opposing trends across the selected countries for BP and TC (declines in high-income countries and increases in some low- and middle-income coun- tries). Regardless of the favorable changes in some countries, the effect of these 2 risk factors on the PAFs for CVD remains high. In contrast, both obesity and DM have increased with time in almost all of the countries. These latter risk factors are likely to contribute more fully to a corresponding increase in the healthcare burden imposed by CVD. Smoking prevalence also remains excessively high, particularly among Asian men. Findings suggest that the effects of all risk factors on CVD have not diminished in importance over time. As a problem that is shared globally, coordinated efforts to design worldwide campaigns to develop policy and programs for the promotion of healthy lifestyles (including smoking cessation, improvements in nutrition, and encouragement of physical activity) are clearly warranted.

\section{References}

1. Mendis S, Puska P, Norrving B. Global atlas on cardiovascular disease prevention and control. World Health Organization, Geneva, 2011.

2. Yusuf S, Hawken S, Ounpuu S, Dans T, Avezum A, Lanas F, et al. Effect of potentially modifiable risk factors associated with myocardial infarction in 52 countries (the INTERHEART study): Case-control study. Lancet 2004; 364: 937-952.

3. Chiuve SE, McCullough ML, Sacks FM, Rimm EB. Healthy lifestyle factors in the primary prevention of coronary heart disease among men: Benefits among users and nonusers of lipid-lowering and antihypertensive medications. Circulation 2006; 114: 160-167.

4. Critchley J, Liu J, Zhao D, Wei W, Capewell S. Explaining the increase in coronary heart disease mortality in Beijing between 1984 and 1999. Circulation 2004; 110: 1236-1244.

5. Reddy KS. Cardiovascular disease in non-Western countries. $N$ Engl $J$ Med 2004; 350: 2438-2440.

6. Ueshima H, Sekikawa A, Miura K, Turin TC, Takashima N, Kita Y, et al. Cardiovascular disease and risk factors in Asia: A selected review. Circulation 2008; 118: $2702-2709$.

7. Woodward M, Martiniuk A, Lee CM, Lam TH, Vanderhoorn S, Ueshima $\mathrm{H}$, et al. Elevated total cholesterol: Its prevalence and population attributable fraction for mortality from coronary heart disease and ischaemic stroke in the Asia-Pacific region. Eur J Cardiovasc Prev Rehabil 2008; 15: 397-401.

8. The World Bank. World data bank: World develpoment indicators. http://databank.worldbank.org/data/views/variableselection/ selectvariables.aspx? source $=$ world-development-indicators $($ accessed on 6 August, 2013).

9. Finucane MM, Stevens GA, Cowan MJ, Danaei G, Lin JK, Paciorek $\mathrm{CJ}$, et al. National, regional, and global trends in body-mass index since 1980: Systematic analysis of health examination surveys and epidemiological studies with 960 country-years and 9.1 million participants. Lancet 2011; 377: 557-567.

10. Danaei G, Finucane MM, Lu Y, Singh GM, Cowan MJ, Paciorek CJ, et al. National, regional, and global trends in fasting plasma glucose 
and diabetes prevalence since 1980: Systematic analysis of health examination surveys and epidemiological studies with 370 countryyears and 2.7 million participants. Lancet 2011; 378: 31-40.

11. Farzadfar F, Finucane MM, Danaei G, Pelizzari PM, Cowan MJ, Paciorek CJ, et al. National, regional, and global trends in serum total cholesterol since 1980: Systematic analysis of health examination surveys and epidemiological studies with 321 country-years and 3.0 million participants. Lancet 2011; 377: 578-586.

12. Danaei G, Finucane MM, Lin JK, Singh GM, Paciorek CJ, Cowan MJ, et al. National, regional, and global trends in systolic blood pressure since 1980: Systematic analysis of health examination surveys and epidemiological studies with 786 country-years and 5.4 million participants. Lancet 2011; 377: 568-577.

13. World Health Organization. WHO report on the global tobacco epidemic, 2013: Enforcing bans on tobacco advertising, promotion and sponsorship. WHO, 2013.

14. OECD. Health at a glance 2005: OECD indicators. OECD Publishing, 2005.

15. OECD. Health at a glance 2007: OECD indicators. OECD Publishing, 2007.

16. OECD. Health at a glance 2009: OECD indicators. OECD Publishing, 2009.

17. OECD. Health at a glance 2011: OECD indicators. OECD Publishing, 2011.

18. OECD/WHO. Tobacco. In: Health at a Glance: Asia/Pacific 2012. OECD/WHO, 2012.

19. Morrow M, Barraclough S. Tobacco control and gender in south-east Asia. Part II: Singapore and Vietnam. Health Promot Int 2003; 18: 373-380.

20. Qian J, Cai M, Gao J, Tang S, Xu L, Critchley JA. Trends in smoking and quitting in China from 1993 to 2003: National Health Service Survey data. Bull World Health Organ 2010; 88: 769-776.

21. World Health Organization. WHO report on the global tobacco epidemic, 2008: The MPOWER package. WHO, 2008.

22. World Health Organization. WHO report on the global tobacco epidemic, 2009: Implementing smoke-free environments. WHO, 2009.

23. Cancer Research UK. Smoking statistics. http: //www.cancerresearchuk. org/cancer-info/cancerstats/types/lung/smoking/lung-cancer-andsmoking-statistics\#source9 (accessed on 6 August, 2013).

24. Office on Smoking and Health (US). Women and smoking: A report of the Surgeon General. 2001.

25. Martiniuk AL, Lee CM, Lawes CM, Ueshima H, Suh I, Lam TH, et al. Hypertension: Its prevalence and population-attributable fraction for mortality from cardiovascular disease in the Asia-Pacific region. J Hypertens 2007; 25: 73-79.

26. Ueshima H, Tatara K, Asakura S, Okamoto M. Declining trends in blood pressure level and the prevalence of hypertension, and changes in related factors in Japan, 1956-1980. J Chronic Dis 1987; 40: 137-147.

27. Egan BM, Zhao Y, Axon RN. US trends in prevalence, awareness, treatment, and control of hypertension, 1988-2008. JAMA 2010; 303: $2043-2050$.

28. Brown IJ, Tzoulaki I, Candeias V, Elliott P. Salt intakes around the world: Implications for public health. Int J Epidemiol 2009; 38: 791 813.

29. Ueshima H. Explanation for the Japanese paradox: Prevention of increase in coronary heart disease and reduction in stroke. $J$ Atheroscler Thromb 2007; 14: 278-286.

30. Miura K, Nagai M, Ohkubo T. Epidemiology of hypertension in Japan. Circ J 2013; 77: 2226-2231.

31. Cameron A, Roubos I, Ewen M, Mantel-Teeuwisse AK, Leufkens HG, Laing RO. Differences in the availability of medicines for chronic and acute conditions in the public and private sectors of developing countries. Bull World Health Organ 2011; 89: 412-421.

32. Fujiyoshi A, Ohkubo T, Miura K, Murakami Y, Nagasawa SY, Okamura $\mathrm{T}$, et al. Blood pressure categories and long-term risk of cardiovascular disease according to age group in Japanese men and women. Hypertens Res 2012; 35: 947-953.

33. Khoo KL, Tan H, Liew YM, Deslypere JP, Janus E. Lipids and coronary heart disease in Asia. Atherosclerosis 2003; 169: 1- 10.

34. Popkin BM, Horton S, Kim S, Mahal A, Shuigao J. Trends in diet, nutritional status, and diet-related noncommunicable diseases in China and India: The economic costs of the nutrition transition. Nutr Rev 2001; 59: 379-390.

35. Gaziano TA, Bitton A, Anand S, Abrahams-Gessel S, Murphy A. Growing epidemic of coronary heart disease in low- and middle-income countries. Curr Probl Cardiol 2010; 35: 72-115.
36. Yamada M, Wong FL, Kodama K, Sasaki H, Shimaoka K, Yamakido M. Longitudinal trends in total serum cholesterol levels in a Japanese cohort, 1958-1986. J Clin Epidemiol 1997; 50: 425-434.

37. Tajima N, Kurata H, Nakaya N, Mizuno K, Ohashi Y, Kushiro T, et al. Pravastatin reduces the risk for cardiovascular disease in Japanese hypercholesterolemic patients with impaired fasting glucose or diabetes: Diabetes subanalysis of the Management of Elevated Cholesterol in the Primary Prevention Group of Adult Japanese (MEGA) Study. Atherosclerosis 2008; 199: 455-462.

38. Brunner NW, Ramanathan K, Wang H, Quan H, Khan NA. Effectiveness of statin prescribing on reducing mortality in South asian, chinese, and white patients with diabetes. Can J Cardiol 2013; 29: 920-926.

39. Whincup PH, Emberson JR, Lennon L, Walker M, Papacosta O, Thomson A. Low prevalence of lipid lowering drug use in older men with established coronary heart disease. Heart 2002; 88: 25-29.

40. Ma J, Sehgal NL, Ayanian JZ, Stafford RS. National trends in statin use by coronary heart disease risk category. PLoS Med 2005; 2: 31 .

41. Bhatt DL, Steg PG, Ohman EM, Hirsch AT, Ikeda Y, Mas JL, et al. International prevalence, recognition, and treatment of cardiovascular risk factors in outpatients with atherothrombosis. JAMA 2006; 295: $180-189$.

42. Seshasai SR, Kaptoge S, Thompson A, Di Angelantonio E, Gao P, Sarwar N, et al. Diabetes mellitus, fasting glucose, and risk of causespecific death. N Engl J Med 2011; 364: 829-841.

43. Ramachandran A, Ma RC, Snehalatha C. Diabetes in Asia. Lancet 2010; 375: 408-418.

44. Huxley R, James WP, Barzi F, Patel JV, Lear SA, Suriyawongpaisal $\mathrm{P}$, et al. Ethnic comparisons of the cross-sectional relationships between measures of body size with diabetes and hypertension. Obes Rev 2008; 1: 53-61.

45. Yoon KH, Lee JH, Kim JW, Cho JH, Choi YH, Ko SH, et al. Epidemic obesity and type 2 diabetes in Asia. Lancet 2006; 368: 1681 1688.

46. Chan JC, Malik V, Jia W, Kadowaki T, Yajnik CS, Yoon KH, et al. Diabetes in Asia: Epidemiology, risk factors, and pathophysiology. JAMA 2009; 301: 2129-2140.

47. Ma RC, Chan JC. Pregnancy and diabetes scenario around the world: China. Int J Gynaecol Obstet 2009; 104: 15.

48. Ezzati M, Henley SJ, Thun MJ, Lopez AD. Role of smoking in global and regional cardiovascular mortality. Circulation 2005; 112: 489497.

49. Eriksen M, Mackay J, Ross H. The tobacco atlas, 4th edition. 2012.

50. World Health Organization. Global health risks: Mortality and burden of disease attributable to selected major risks. 2009.

51. Gupta M, Singh N, Verma S. South Asians and cardiovascular risk: What clinicians should know. Circulation 2006; 113: e924-e929.

52. Yusuf S, Reddy S, Ounpuu S, Anand S. Global burden of cardiovascular diseases. Part II: Variations in cardiovascular disease by specific ethnic groups and geographic regions and prevention strategies. Circulation 2001; 104: 2855-2864.

53. Sekikawa A, Curb JD, Ueshima H, El-Saed A, Kadowaki T, Abbott $\mathrm{RD}$, et al. Marine-derived n-3 fatty acids and atherosclerosis in Japanese, Japanese-American, and white men: A cross-sectional study. J Am Coll Cardiol 2008; 52: 417-424.

54. Ezzati M, Hoorn SV, Lopez AD, Danaei G, Rodgers A, Mothers CD, et al. Comparative quantification of mortality and burden of disease attributable to selected risk factors. In: Lopez AD, Mathers CD, Ezzati M, Jamison DT, Murray CJL, editors. Global Burden of Disease and Risk Factors. Washington (DC): World Bank, 2006; 241-396.

55. Lim SS, Vos T, Flaxman AD, Danaei G, Shibuya K, Adair-Rohani $\mathrm{H}$, et al. A comparative risk assessment of burden of disease and injury attributable to 67 risk factors and risk factor clusters in 21 regions, 1990-2010: A systematic analysis for the Global Burden of Disease Study 2010. Lancet 2012; 380: 2224-2260.

56. Murray CJ, Lopez AD. Measuring the global burden of disease. $N$ Engl J Med 2013; 369: 448-457.

57. Motlagh B, O'Donnell M, Yusuf S. Prevalence of cardiovascular risk factors in the Middle East: A systematic review. Eur J Cardiovasc Prev Rehabil 2009; 16: 268-280.

58. Gersh BJ, Sliwa K, Mayosi BM, Yusuf S. Novel therapeutic concepts: The epidemic of cardiovascular disease in the developing world: Global implications. Eur Heart J 2010; 31: 642-648.

59. Yang G, Wang Y, Zeng Y, Gao GF, Liang X, Zhou M, et al. Rapid health transition in China, 1990-2010: Findings from the Global Burden of Disease Study 2010. Lancet 2013; 381: 1987-2015. 